\title{
Uso experimental da biomembrana de látex na reconstrução conjuntival
}

\author{
Experimental use of latex biomembrane in conjunctival reconstruction
}

\author{
Erika Christina Canarim M. de Pinho ${ }^{1}$ \\ Sidney Júlio de Faria e Sousa ${ }^{2}$ \\ Fernando Schaud ${ }^{3}$ \\ João-José Lachat ${ }^{4}$ \\ Joaquim Coutinho-Netto ${ }^{5}$
}

${ }^{1}$ Pós-graduanda da Faculdade de Medicina de Ribeirão Preto - Universidade de São Paulo - USP.

${ }^{2}$ Professor do Departamento de Oftalmologia, Otorrinolaringologia e Cirurgia de Cabeça e Pescoço da Faculdade de Medicina de Ribeirão Preto - Universidade de São Paulo - USP.

${ }^{3}$ Pós-graduando da Faculdade de Medicina de Ribeirão Preto - Universidade de São Paulo - USP

${ }^{4}$ Professor do Departamento de Anatomia e Cirurgia da Faculdade de Medicina de Ribeirão Preto - Universidade de São Paulo - USP.

${ }^{5}$ Professor do Departamento de Bioquímica e Imunologia da Faculdade de Medicina de Ribeirão Preto - Universidade de São Paulo - USP.

Endereço para correspondência: Erika Christina Canarim Martha de Pinho, Rua Jamil Gebara 1-25 apto. 61 Bauru (SP) CEP 17017-150

Recebido para publicação em 21.01.2003

Versão revisada recebida em 22.07.2003

Aprovação em 06.11.2003

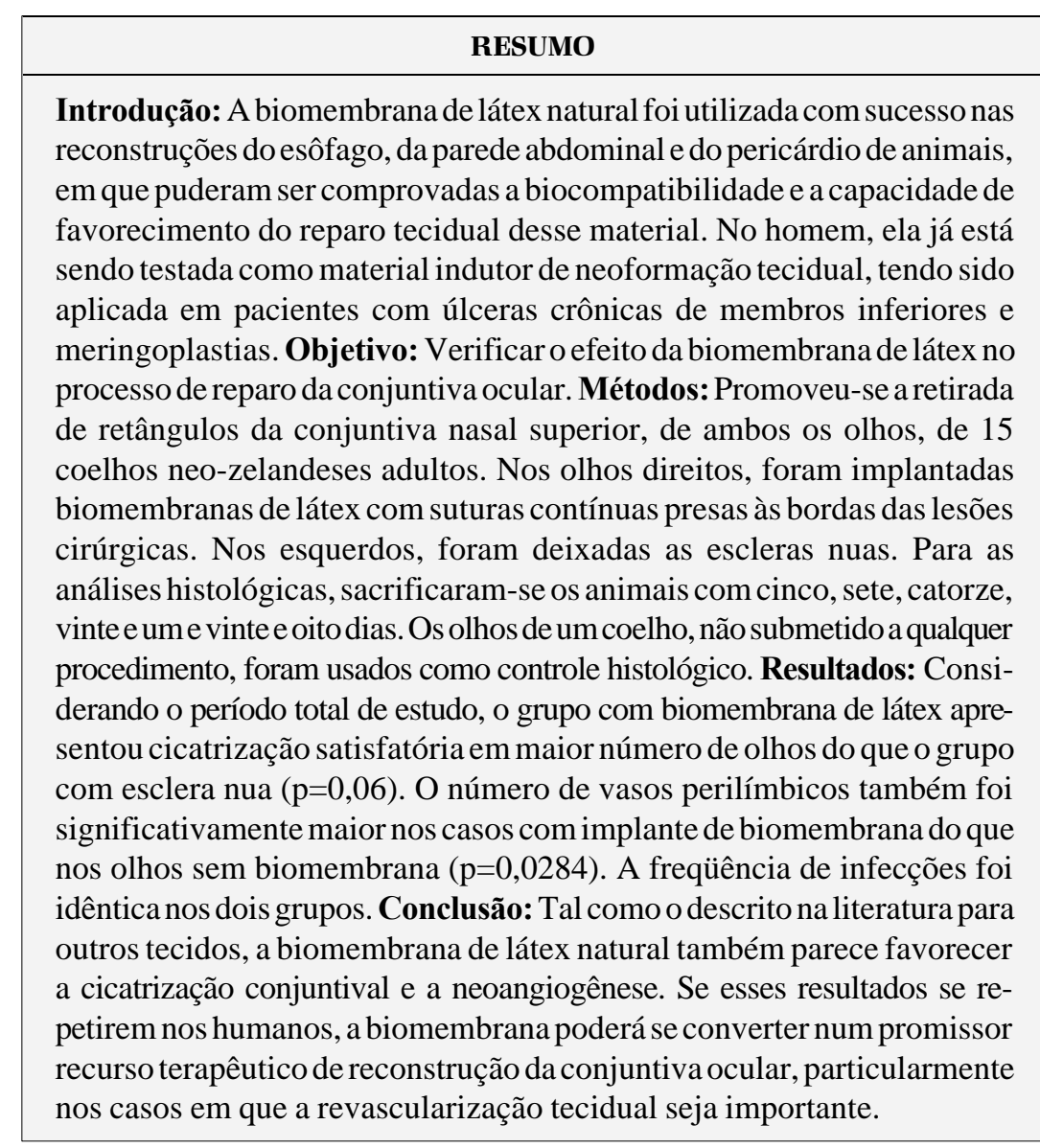

Descritores: Conjuntiva/cirurgia; Cicatriz; Membranas artificiais; Regeneração; Coelhos

\section{INTRODUÇÃO}

A biomembrana de látex natural foi desenvolvida no Departamento de Bioquímica e Imunologia da Faculdade de Medicina de Ribeirão Preto-USP, por um de nós (J.C-N). Ela é confeccionada com o látex extraído da seringueira Hevea brasiliensis, e banhada com polilisina, um policátion que aumenta a permeabilidade e o fluxo microvascular ${ }^{(1-2)}$. Acredita-se que a biomembrana apresente importantes propriedades biológicas, tais como: atividade neoangiogênica, promoção de adesão celular e formação de matriz extracelular ${ }^{(1-2)}$. Em estudos experimentais, a biomembrana favoreceu o reparo de defeitos parciais de esôfago ${ }^{(1-2)}$ e de ressecções extensas de parede abdominal $^{(2)}$, demonstrando inclusive capacidade de substituição parcial 
de pericárdio ${ }^{(3)}$. Também já foi utilizada com sucesso em cirurgias reconstrutoras de membrana timpânica ${ }^{(4)} \mathrm{e} \mathrm{em}$ úlceras de membros inferiores ${ }^{(5-7)}$. Esse material demonstrou ser biocompatível em todos os experimentos já realizados, sem nenhum tipo de reação alérgica ${ }^{(1-9)}$. Isso se deve ao fato dela ser constituída por uma cadeia de poliisoprenóis altamente purificada de proteínas. Os poliisoprenóis são naturalmente encontrados nos tecidos dos animais superiores, na forma de cadeias maiores, tais como esqualeno, ubiquinona e dolicol ${ }^{(8)}$.

O sucesso da aplicação dessa biomembrana na regeneração de tecidos encorajou-nos a estudar a sua eventual atuação na reconstrução da conjuntiva ocular. Por ser de origem vegetal, não teria o potencial de transmissão de doenças infecciosas como a membrana amniótica. Em função disso, fixamos como objetivo deste estudo verificar os seus efeitos no processo de reparo conjuntival de olhos de coelhos.

\section{MÉTODOS}

A biomembrana de látex com polilisina a $0,1 \%$ (Poly-Llysine Hydrobromide, PM 70-140 Kda-Sigma) foi preparada conforme descrito na literatura ${ }^{(1-2,7-8)}$, obtendo-se discos de 4 centímetros de diâmetro e de 0,5 milímetro de espessura, embalados individualmente e esterilizados em óxido de etileno (Figura 1). Imediatamente antes do procedimento cirúrgico, o disco era recortado em fragmentos de 1,5 por 1,0 centímetro.

Utilizou-se dezesseis coelhos neo-zelandeses, albinos, pesando entre dois e três quilos. Quinze coelhos foram submetidos à cirurgia, sob anestesia endovenosa com thiopental sódico. O procedimento constou da exérese de um retalho conjuntival retangular, de 1,5 centímetro de largura, ao longo do limbo, e 1,0 centímetro de comprimento, em direção ao fórnice, no quadrante nasal superior em ambos os olhos. Nos olhos direitos, foram implantados retalhos de biomembrana de látex. Eles

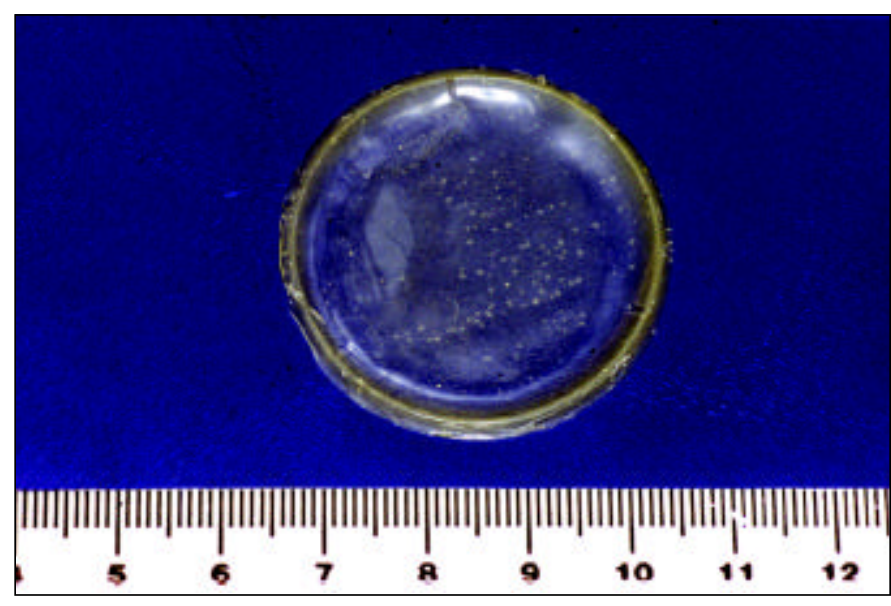

Figura 1 - Observa-se a membrana derivada de látex natural, com adição de polilisina a $0,1 \%$, preparada para uso oftalmológico, apresentando-se em discos de $4 \mathrm{~cm}$ de diâmetro e $0,5 \mathrm{~mm}$ de espessura. Antes de sua aplicação sobre a esclera nua no olho direito de quinze coelhos, recorta-se o material nas dimensões $1,0 \times 1,5 \mathrm{~cm}$ eram suturados às bordas da ressecção, com sutura contínua de mononylon dez zeros. Os olhos esquerdos não foram reconstruídos, permanecendo com a esclera nua.

No pós-operatório, os coelhos receberam colírio de neomicina, polimixina B e dexametasona (Maxitrol ${ }^{\circledR}$, Alcon, São Paulo), em ambos os olhos, três vezes ao dia, até a data do sacrifício. Os animais foram divididos em cinco grupos conforme a época do sacrifício. Deste modo, o grupo I foi sacrificado no $5^{\circ}$ dia, o II no $7^{\circ}$ dia, o III no $14^{\circ}$ dia, o IV no $21^{\circ}$ dia e o V no $28^{\circ}$ dia após a cirurgia. Os olhos do coelho que não sofreu cirurgia alguma serviram de controle de normalidade. Os cortes histológicos foram realizados na região central da ferida cirúrgica, contendo esclera, córnea e limbo. O material foi corado com hematoxilina-eosina (HE) e tricrômico de Massom (TM). A análise foi realizada por dois observadores independentes, e um terceiro era requisitado em caso de incongruência nos resultados.

Os itens analisados nos cortes histológicos foram: (1) infiltrado inflamatório do estroma conjuntival, classificado em $1+$ (muito leve), 2+ (leve), 3+ (moderado) e 4+ (intenso), e em tipo agudo (neutrófilo e eosinófilo), crônico (linfócito, plasmócito e macrófago) e misto (agudo combinado a crônico); (2) presença de células caliciformes; (3) espessura da camada epitelial, sendo considerada camada fina, com 1 a 2 células, intermediária, com 3 a 4 células, e espessa, com 5 a 6 células;. (4) desepitelização residual, medida com ocular micrometrada, com aumento de dez vezes, no microscópio óptico Olympus CHKBI45; e, (5) número de vasos perilímbicos por campo de dez aumentos, no mesmo microscópio.

Considerou-se como reação inflamatória exacerbada os olhos que apresentavam infiltrados do tipo agudo e misto, com intensidade de 3+ ou 4+ até catorze dias de experimento, ou com qualquer intensidade após catorze dias de experimento. $\mathrm{E}$ ainda, os casos com infiltrado crônico, com intensidade de 3+ ou 4+ após 14 dias de experimento. Considerou-se como infecção os casos com reação inflamatória exacerbada associada a erosões e/ou necrose celulares. O reparo conjuntival foi considerado satisfatório quando atingiu as seguintes características: (1) epitélio com espessura mínima de três células; (2) presença de células caliciformes; (3) desepitelização menor ou igual a 1.250 micrômetros.

\section{RESULTADOS}

A análise histológica dos olhos controle ofereceu os seguintes dados para comparação: epitélio conjuntival peri-límbico composto de três a quatro células, entremeadas por células caliciformes, sobre substância própria espessa. À medida que se caminha para o fórnice, o epitélio torna-se mais espessado, atingindo composição de seis a sete células, com maior proporção de células caliciformes (Figura 2).

Em todos os olhos onde foram implantadas as biomembranas, elas permaneceram até o final do experimento, presas pelos pontos cirúrgicos, e não aderidas ao tecido subjacente. Uma 
fina camada de material fibrinoso recobria-as em ambas as faces (Figura 3). A epitelização ocorreu sob a biomembrana em todos os coelhos.

A tabela 1 apresenta os principais dados histológicos dos 15 coelhos com implante de biomembrana. A tabela 2 mostra os dados correspondentes dos olhos com esclera nua.

Três olhos do grupo da biomembrana de látex (coelhos 2, 9 e 15) e cinco olhos do grupo da esclera nua (coelhos 3, 8, 13, 14 e15) apresentaram infecção. Foram observados infiltrados inflamatórios exacerbados isolados num olho com (coelho 11) e outro sem biomembrana (coelho 6).

Dos quinze olhos submetidos ao implante de biomembrana, nove apresentaram cicatrização satisfatória (coelhos 1, 3, 4, 5, 9, $12,13,14 \mathrm{e} 15)$, enquanto que dos quinze olhos com esclera nua apenas três apresentaram resultado satisfatório (coelhos 9,12 , 13). Essa diferença foi estatisticamente significante em nível de $\mathrm{p}=0,06$, no teste exato de Fisher. O número médio de vasos por campo foi de 12 nos olhos com a biomembrana e de 6 onde ela não foi utilizada. Esta diferença também se revelou estatisticamente significante $(\mathrm{p}=0,0284)$, no teste $t$ de Student.

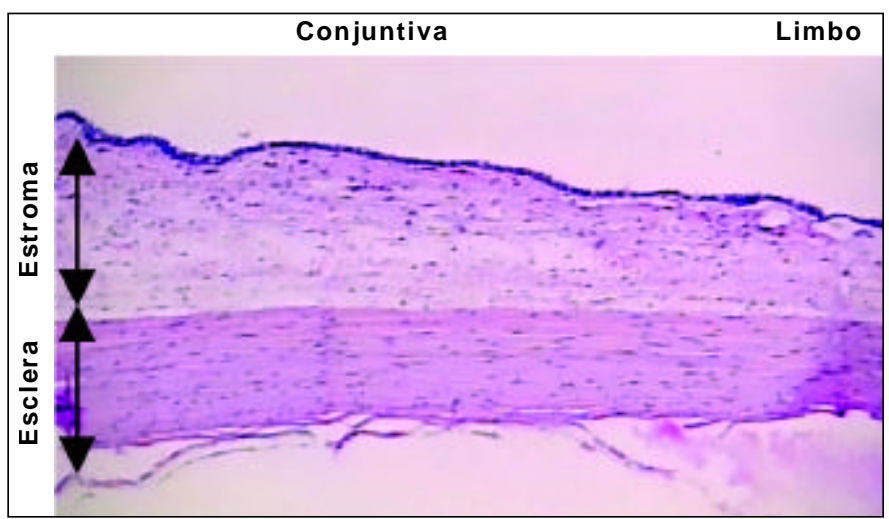

Figura 2 - Fotomicrografia da conjuntiva bulbar do olho de coelho adulto normal, sem ser submetido a procedimento cirúrgico. Observa-se a presença do epitélio cilíndrico estratificado, com células caliciformes nas camadas superficiais, seguido de estroma espesso e esclera. Vêse também a transição da conjuntiva para o limbo. Coloração: Hematoxilina e Eosina. Aumento: 100X

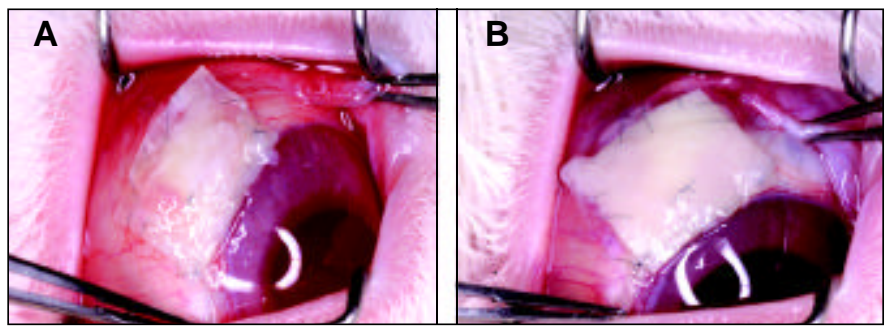

Figura 3 - Seguimento pós-operatório dos olhos com a biomembrana de látex em olhos de coelhos. Em A, observa-se o olho no sétimo dia pósoperatório, onde é possível ver o material fibrinoso sob a biomembrana, com essa iniciando a perda da característica translúcida da biomembrana de látex. Em B, observa-se o olho no décimo quarto dia pós-operatório, com a biomembrana apresentando-se totalmente opaca, com material esbranquiçado e denso sob o implante

\section{DISCUSSÃO}

Para que o epitélio recubra a ferida da conjuntiva é fundamental a existência de uma matriz extracelular provisional ${ }^{(10)}$. Na prática oftalmológica, valendo-se de corantes vitais, consegue-se avaliar o recobrimento epitelial, mas não as características íntimas do processo de reparação conjuntival, como a espessura da substância própria, a espessura da camada epitelial, a presença de células caliciformes e a neovascularização. As análises histológicas trazem, então, elementos adicionais, não fornecidos pela lâmpada de fenda.

Os métodos atualmente mais utilizados na reconstrução da conjuntiva são os enxertos autólogos da mesma e os implantes de membrana amniótica. Os primeiros consagraram-se como procedimentos altamente eficazes, mas que, em alguns casos, não podem ser realizados devido à escassez de tecido ${ }^{(11)}$. Os segundos, não apresentam esse problema, mas, por serem de natureza humana, trazem consigo a potencialidade da transmissão de doenças ao receptor ${ }^{(12)}$. A biomembrana de látex além de favorecer a cicatrização, estaria livre destes dois inconvenientes.
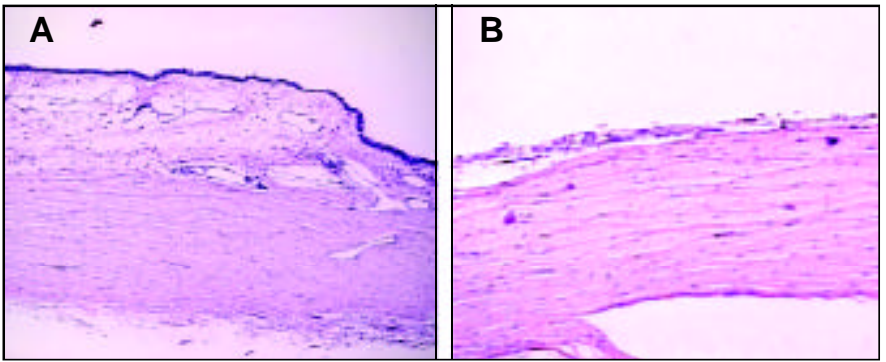

Figura 4 - Fotomicrografias da conjuntiva bulbar de olho de coelho aos cinco dias de pós-operatório. Em A, observa-se olho com implante de biomembrana de látex apresentando epitélio totalmente reconstituído, presença de células caliciformes, estroma espesso e grande quantidade de vasos. Em B, observa-se olho sem implante de biomembrana de látex, com esclera e pequena quantidade de estroma conjuntival, com ausência de células epiteliais e caliciformes. Coloração: Hematoxilina e Eosina. Aumento: 100X
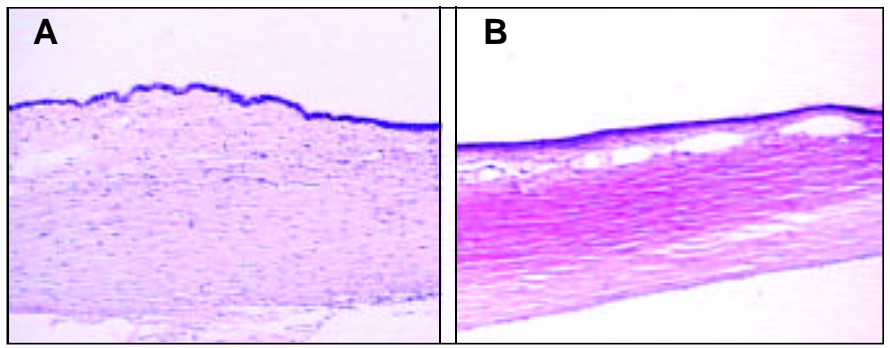

Figura 5 - Fotomicrografias da conjuntiva bulbar de olho de coelho aos catorze dias de pós-operatório. Em A, observa-se olho com implante de biomembrana de látex, com epitélio refeito, presença de células caliciformes, sobre estroma de espessura intermediária. Em B, observase olho sem implante de biomembrana de látex, apresentando epitélio reconstituído, com células caliciformes esparsas, sobre estroma de espessura intermediária. Coloração: Hematoxilina e Eosina. Aumento: 100X. Observa-se que a conjuntiva do olho com implante de biomembrana de látex apresenta-se mais semelhante à conjuntiva mostrada na Figura 3, do que a conjuntiva do olho sem o implante 


\begin{tabular}{|c|c|c|c|c|c|c|}
\hline \multirow[b]{2}{*}{ Sacrifício } & \multirow[b]{2}{*}{ Coelhos } & \multicolumn{5}{|c|}{ Histologia } \\
\hline & & $\begin{array}{l}\text { Infiltrado } \\
\text { inflamatório }\end{array}$ & $\begin{array}{c}\text { Desepitelização } \\
\text { residual }\end{array}$ & $\begin{array}{c}\text { Células } \\
\text { caliciformes }\end{array}$ & $\begin{array}{c}\text { Espessura } \\
\text { epitelial }\end{array}$ & $\begin{array}{c}\text { Vasos } \\
\text { no leito }\end{array}$ \\
\hline 5 dias & $1^{\#}$ & 1+, agudo & 980 & + & 3-4 & 5 \\
\hline \multirow[t]{2}{*}{ (grupo I) } & 2 & $3+$, agudo* & 0 & 0 & $1-2$ & 2 \\
\hline & $3^{\#}$ & $1+$, agudo & 0 & + & $3-4$ & 7 \\
\hline \multirow{3}{*}{$\begin{array}{l}7 \text { dias } \\
\text { (grupo II) }\end{array}$} & $4^{\#}$ & $1+$, agudo & 0 & + & $5-6$ & 7 \\
\hline & $5^{\#}$ & $1+$, agudo & 0 & + & $3-4$ & 4 \\
\hline & 6 & $2+$, agudo & 2380 & 0 & $2-3$ & 10 \\
\hline \multirow{3}{*}{$\begin{array}{l}14 \text { dias } \\
\text { (grupo III) }\end{array}$} & 7 & 0 & 968 & + & $2-3$ & 6 \\
\hline & 8 & 0 & 1785 & + & $3-4$ & 5 \\
\hline & $9^{\#}$ & $2+$, misto*$^{*}$ & 1189 & + & $5-6$ & 20 \\
\hline \multirow{3}{*}{$\begin{array}{l}21 \text { dias } \\
\text { (grupo IV) }\end{array}$} & 10 & $1+$, misto & 0 & + & $2-3$ & 10 \\
\hline & 11 & $2+$, agudo & 4471 & 0 & 0 & 11 \\
\hline & $12^{\#}$ & $1+$, misto & 0 & 0 & $4-5$ & 12 \\
\hline \multirow{3}{*}{$\begin{array}{l}28 \text { dias } \\
\text { (grupo V) }\end{array}$} & $13^{\#}$ & 0 & 0 & + & $4-5$ & 27 \\
\hline & $14^{\#}$ & 0 & 0 & + & $3-4$ & 29 \\
\hline & $15^{\#}$ & $3+$, misto* & 610 & 0 & $4-6$ & 26 \\
\hline
\end{tabular}

\begin{tabular}{|c|c|c|c|c|c|c|}
\hline Sacrifício & Coelhos & $\begin{array}{c}\text { Infiltrado } \\
\text { inflamatório }\end{array}$ & $\begin{array}{l}\text { Desepitelização } \\
\text { residual }\end{array}$ & $\begin{array}{l}\text { Histologia } \\
\text { células } \\
\text { caliciformes }\end{array}$ & $\begin{array}{c}\text { Espessura } \\
\text { epitelial }\end{array}$ & $\begin{array}{c}\text { Vasos } \\
\text { no leito }\end{array}$ \\
\hline \multirow{3}{*}{$\begin{array}{l}5 \text { dias } \\
\text { (grupo I) }\end{array}$} & 1 & 0 & 4506 & 0 & $1-2$ & 1 \\
\hline & 2 & $1+$, agudo & 9835 & 0 & $1-2$ & 0 \\
\hline & 3 & $2+$, agudo* & 5129 & 0 & $1-2$ & 5 \\
\hline \multirow{3}{*}{$\begin{array}{l}7 \text { dias } \\
\text { (grupo II) }\end{array}$} & 4 & $1+$, agudo & 0 & 0 & $1-2$ & 1 \\
\hline & 5 & $1+$, agudo & 0 & + & $2-3$ & 1 \\
\hline & 6 & $3+$, misto & 7822 & 0 & $1-2$ & 7 \\
\hline \multirow{3}{*}{$\begin{array}{l}14 \text { dias } \\
\text { (grupo III) }\end{array}$} & 7 & $1+$, misto & 1132 & + & $2-3$ & 0 \\
\hline & 8 & $2+$, misto* & 0 & + & $2-3$ & 3 \\
\hline & $9^{\#}$ & $1+$, misto & 1207 & + & $5-6$ & 6 \\
\hline \multirow{3}{*}{$\begin{array}{l}21 \text { dias } \\
\text { (grupo IV) }\end{array}$} & 10 & 0 & 0 & + & $2-3$ & 5 \\
\hline & 11 & $1+$, agudo & 0 & + & $2-3$ & 4 \\
\hline & $12^{\#}$ & $1+$, misto & 0 & + & $3-4$ & 8 \\
\hline \multirow{3}{*}{$\begin{array}{l}28 \text { dias } \\
\text { (grupo V) }\end{array}$} & $13^{\#}$ & 3+, crônico* & 0 & + & $3-4$ & 9 \\
\hline & 14 & 3+, crônico* & 1297 & + & $4-5$ & 22 \\
\hline & 15 & $2+$, agudo* & 493 & 0 & $2-3$ & 13 \\
\hline
\end{tabular}

No presente trabalho, fica claro que os 28 dias de estudo não foram suficientes para a recuperação total das feridas cirúrgicas conjuntivais, tanto nos casos com biomembrana quanto nos sem. Entretanto, a recuperação foi satisfatória em $60 \%$ dos olhos com biomembrana (9 em 15 casos) enquanto que, nos olhos com esclera nua, ela foi satisfatória em apenas $20 \%$ dos mesmos ( 3 em 15 casos). Isto sugere que a biomembrana de látex, à semelhança do que ocorre em outros tecidos, também promova a aceleração da cicatrização na conjuntiva.
Outro fato relevante foi que o número médio de vasos por campo óptico na ferida cirúrgica dos olhos com biomembrana foi o dobro desse mesmo número nos olhos com esclera nua. Isso vem reforçar as suspeitas da literatura de que a biomembrana realmente tenha propriedades neoangiogênicas. Uma vez que o processo de reparo tecidual não ocorre sem neoangiogênese, que a vasculatura neoformada corresponde a sessenta por cento de todo o tecido de reparo ${ }^{(13)}$, e que as células caliciformes dependem de aporte sangüíneo para a sua manutenção ${ }^{(14-15)}$, a 
biomembrana de látex parece promover condições biológicas satisfatórias para a recuperação conjuntival. Entretanto, se o estímulo à neoangiogênese é um fenômeno positivo em termos de cicatrização, ainda se desconhece sua importância nos casos onde ele seja teoricamente pouco desejado, como nos pterígios, simbléfaros recidivantes ${ }^{(16)}$ e tumores ${ }^{(17)}$. Vale ressaltar que, após a fase de remodelagem no processo de cicatrização, a rica vascularização regride a níveis semelhantes ou menores que aos anteriores à lesão ${ }^{(10)}$.

Quanto às infecções, uma de nossas preocupações era se a biomembrana de látex aumentaria as chances de infecção ocular, tal como ocorre com as lentes de contato e outros materiais estranhos, de uso médico geral, implantados no corpo humano. Felizmente, os nossos resultados não mostraram diferenças significativas entre os olhos com e sem o implante de biomembrana, sugerindo que esta, além de ser bem tolerada, não deve aumentar as chances de infecção.

Finalizando, as células caliciformes estão diretamente relacionadas à funcionalidade da conjuntiva. São facilmente destruídas pelas infecções e pela diminuição de aporte sanguíneo local ${ }^{(14-15)}$. Quando o processo de reparo leva a uma cicatriz fibrosa e avascular, também há menor probabilidade delas serem restauradas ${ }^{(15)}$. É por isso que elas participaram dos nossos critérios de avaliação da evolução do reparo conjuntival. No presente estudo, as células caliciformes só se fizeram presentes quando o epitélio já estava bem organizado.

É necessário aprofundar ainda mais os estudos dos efeitos da biomembrana de látex no olho, comparando-os às outras técnicas disponíveis de reconstrução da superfície ocular, como, por exemplo, os transplantes conjuntivais autólogos e os implantes de membrana amniótica, estudos esses já em andamento. Se esses resultados se repetirem nos humanos, a membrana poderá se converter num promissor recurso terapêutico de reconstrução da conjuntiva ocular, particularmente nos casos em que seja importante a revascularização tecidual.

\section{CONCLUSÃO}

No presente estudo em coelhos, observou-se que a biomembrana de látex natural promoveu a reconstituição conjuntival, quando comparada ao grupo controle. De acordo com o descrito na literatura para outros tecidos, a biomembrana de látex natural também parece favorecer a cicatrização conjuntival e a neoangiogênese.

Para que a biomembrana possa se converter num promissor recurso terapêutico de reconstrução da conjuntiva ocular, aguardamos resultados de estudos que já estão em andamento, comparando os efeitos desse material com outras modalidades cirúrgicas, como o transplante de conjuntiva, ainda em coelhos. Também estão sendo propostos protocolos de pesquisas envolvendo humanos.

\section{AGRADECIMENTOS}

Sra. Silvia Helena Epifânio, Sra. Vera Lucia Aguillar Epifânio, Sra. Izilda Rodrigues Violante, Sra. Vani Maria Alves Correia, Prof. Dr. Rumio Taga, Sra. Tânia Mary Cestari.

\section{ABSTRACT}

Introduction: The biomembrane of natural latex is believed to promote neoformation of biological tissues and to be biocompatible. In animal studies, enhancement of wound healing in the esophagus, peritoniostomy, and pericardiostomy has been observed. It was used in chronic phlebopatic cutaneous ulcer and otologic surgeries in human subjects. Purpose: To study the effect of biomembrane of natural latex in ocular surface. Methods: In fifteen New Zealand white rabbits, the superior nasal conjunctiva was removed from both eyes. In the right eyes, the biomembrane of natural latex was sutured to the conjunctiva with continuous 10.0 monofilament thread. In the left eye, the sclera was left bare. The rabbits were sacrified and the eyes were submitted to histological analysis on days five, seven, fourteen, twenty-one and twenty-eight. The eyes of a rabbit with no surgery were enucleated and sent for histological analysis of the normal conjunctiva. Results: Considering the whole period of the experiment, the number of eyes with satisfactory healing was greater in the biomembrane group than in the bare sclera group $(\mathrm{p}=0.06)$. The number of perilimbic vessels was significantly higher in the biomembrane group than in the bare sclera group $(\mathrm{p}=0.0284)$. The infection rate was similar in both groups. Conclusion: Similar to prior studies, the biomembrane of natural latex seemed to benefit conjunctival reconstruction and neoangiogenesis. Depending on the results using human eyes, this material might be a new type of therapeutic resource for conjunctival replacement, especially in cases of desirable tissue revascularization.

Keywords: Conjunctiva/surgery; Cicatrix; Membranes, artificial; Regeneration; Rabbits

\section{REFERÊNCIAS}

1. Mrué, F. Neoformação tecidual induzida por biomembrana de látex natural com polilisina. Aplicabilidade em neoformação esofágica e da parede abdominal. Estudo experimental em cães [tese]. Ribeirão Preto: Universidade de São Paulo; 2000.

2. Mrué F. Substituição do esôfago cervical por prótese biossintética de látex. Estudo experimental em cães. [tese]. Ribeirão Preto: Universidade de São Paulo; 1996.

3. Sader SL, Coutinho Netto J, Barbieri Neto J, Mazzetto AS, Alves Junior PA, Vanni JC, Sader AA. Substituição parcial do pericárdio de cães por membrana de látex natural. Rev Bras Cir Cardiovasc 2000;15:338-44.

4. Oliveira JAA, Hipólito MA, Coutinho-Netto J. La regeneration du tympan avec l'utilization de matériel biosynthétique nouveau. In: Congres Français d'Otorhino-laringologie et de chirurgie de la face et du cou. Paris 1999; Annais. p. 273.

5. Frade MA, Valverde RV, Assis RV, Coutinho Netto J, Foss NT. Chronic phlebophatic cutaneous ulcer: a therapeutic proposal. Int J Dermatol 2001;40: 237-40. 
6. Potério Filho J, Silveira SF, Potério GM, Mrué F, Coutinho Netto J. O uso do látex com polilisina $0,1 \%$ na cicatrização de úlceras isquêmicas. Rev Bras Angiol Cir Vasc 1999; (Suppl):S156Frade, MAC. Úlcera de perna: caracterização clínica e perfil imunohistopatológico da cicatrização na presença da biomembrana de látex natural da seringueira Hevea brasiliensis [tese]. Ribeirão Preto: Universidade de São Paulo; 2003.

7. Mente ED. Desenvolvimento do protótipo de dispositivo para macroencapsulamento de ilhotas pancreáticas a partir de biomembrana natural de látex [tese]. Ribeirão Preto: Universidade de São Paulo; 2002.

8. Lachat J-J, Mrué F, Thomazini JA, Zborowski AC, Ceneviva R, CoutinhoNetto J. Morphological and biochemical studies of the biocompability of a membrane manufactured from the latex of Hevea brasiliensis. Acta Microsc 1997;6(Suppl B):758-9.

9. Forrest, L. Current concepts in soft connective tissue wound. Br J Surg 1983; 70:133-40.
10. Donald TH, Tan MD. Ocular surface transplantation techniques for pterygium surgery. In: Buratto L, Phillips RL, Carito G. Pterygium surgery. Philadelphia: Slack; 2000. p.125-42.

11. Solomon A, Tseng SCG. Amniotic transplantation in pterygium surgery. In: Buratto L, Phillips RL, Carito G. Pterygium surgery. Philadelphia: Slack; 2000. p.143-56.

12. Arnold F, West DC. Angiogenesis in wound healing. Pharmacol Ther 1991; 52:407-22.

13. Tseng SCG. Staging of conjunctival squamous metaplasia by impression citology. Ophthalmology 1985;92:728-33.

14. Tseng SCG, Hirst LW, Maumenee AE, Kenyon KR, Sun TT, Green WR Possible mechanisms for the loss of globet cells in mucin-deficient disorders. Ophthalmology 1984;91:545-52.

15. Neves RA, Foster CS. Ceratoconjuntivites cicatriciais. In: Belfort Junior R, Kara-José N. Córnea clínica e cirúrgica. São Paulo: Roca; 1996. p.301-8.

16. Erwenne CM, Belfort Junior R. Tumores. In: Belfort Junior R, Kara-José N. Córnea clínica e cirúrgica. São Paulo: Roca; 1996. p.413-8.

\section{Congresso da Associação Centro Oeste de Oftalmologia}

\section{Congresso da Sociedade Brasiliense de Offalmologia}

\section{Simpósio da Sociedade Centro-Oeste de Glaucoma}

\section{4 e 15 de Maio de 2004 Academia de Tênis de Brasília}

INFORMAÇÕES: Tels.: (61) 248-4030/81 16-3304 - Dr. Hilton Medeiros

(61) 248-4030/346-6971 (Ana Paula) - Dr. Geraldo Magela Vieira 